\title{
Neurological Effect and Clinical Manifestations of COVID-19 in Elderly Population
}

\author{
Ranita Rusydina Daroh ${ }^{1}$, Dede Renovaldi ${ }^{2}$ \\ 1) General Practitioner, Ananda Bekasi Hospital \\ 2) Department of Biomedic, Faculty of Medicine and Health, Universitas Muhammadiyah Jakarta \\ *Corresponding author: ranitarusydina@gmail.com
}

\begin{abstract}
Background: Currently there is a new world health crisis which is urgent due to the spread of severe acute respiratory syndrome coronavirus 2 (SARS-CoV-2), a novel coronavirus. The elderly can be presented as a group of patients at high risk for developing covid-19 with progressive and rapid clinical deterioration including neurological manifestations. Many reports have emerged showing that SARS-CoV-2 infection has an impact on neurological function, and even causes serious neurological damage. Purposes: to investigate the possible correlation between the aging process to the severity of neurological deterioration experienced in COVID-19 infection specifically by elderly people. Methods: literature searching was conducted through PubMed, MedLine, and Embase. Results: Regardless of age, the infection of SARS-CoV-2 to both central and peripheral nervous system could lead into a range of neurological deteriorations, in which also ranging in forms and severity. Conclusion: In elderly patients, despite of comorbidities, the natural degeneration process is likely being a risk factor of more severe neurological symptoms of Covid-19 infection.
\end{abstract}

Keywords: Covid-19, Sars-CoV-2, Neurological Manifestations, Elderly

\section{INTRODUCTION}

Over the last few decades, the coronavirus $(\mathrm{CoV})$ has been linked to disease outbreaks that had caused significant health threats in East Asia and Middle East area. Severe acute respiratory syndrome (SARS) and Middle East respiratory syndrome (MERS) started appearing in 2002 and 2012 respectively. Last recent, the new coronavirus, severe acute respiratory syndrome, coronavirus 2 (SARS-CoV-2), which caused the 2019 coronavirus disease (COVID-19), became an outbreak and emerged at the end of 2019, and has been determined as a global health threat that causes pandemic situations in various countries $(1,2)$.

It is believed that COVID-19 is a systemic infection, by which it can infect the whole body organs including nervous system and disrupt its normal function. Naturally, nervous system cannot be easily infected by pathogens because of several immune mechanisms. But during aging, there are some changes in immune and nervous system that lead into a decrease in "protective state of infection", and in this section, SARS-CoV-2 infection (3-6). Moreover, the changes in cardiovascular system during aging, specifically the 
thickening of the blood vessels in brain, could make the symptoms of COVID-19 especially neurological symptoms becoming more severe (7). Some recent studies demonstrated that neurological symptoms were quite often experienced by COVID-19 patients, ranging from mild into severe symptom (8). It is acknowledged that the virus can infect the nervous system by several mechanisms, through direct and indirect pathway and resulting in some forms of Central Nervous System (CNS) and Peripheral Nervous system (PNS) symptoms $(3,8)$. In this review, we will describe the possible correlation between aging process to the severity of neurological deterioration experienced specifically by elderly people. We also mentioned some neurological symptoms based on prior recent studies about the SARS-CoV-2 infection in nervous system.

\section{METHODS}

A literature search was carried out using PubMed, Medline, and Embase sources including 30 articles published mostly in 2020 due to the recentness of new cases of Covid-19. The MeSH terminology used were COVID-19, SARS-CoV2, coronavirus, viral pneumonia, neurological manifestations, degenerative processes and the elderly. Furthermore, 33 articles were selected for review reported in a narrative manner in the form of an in-depth review of the selected topic.

\section{THE VIRUS (SARS-COV-2) AND GENERAL PATHOPHYSIOLOGY}

SARS-CoV-2 is a member of the Coronaviridae family and is included in the Nidovirales. SARS-CoV-2 is considered a new Betacorona virus that can infect humans. The Pylogenetic analysis of the SARS-CoV2 genome showed that the virus was closely related (about $88 \%$ ) to the batderived SARS-like coronavirus found in 2018 in eastern China ((bat-SL-CoVZC45 and bat-SL - CoVZXC21) and is genetically similar to SARS-CoV (79\% similarity) and MERS-CoV. A study showed that no evidence of recombination events was detected in the SARS-CoV2 gene from other bat viruses such as BatCoV RaTG13, SARS-CoV and SARSr -CoVs. Taken together, these findings suggest that bats may have been the original hosts of the virus (9).

ACE2 expressed on renal endothelial cells, myocytes, and pulmonary epithelial cells acts as a receptor on SARS-CoV-2 $(10,11)$. At the early stage of infection, the SARS-CoV-2 virus infected target cells such as nasal and bronchial epithelium cells, and also pneumocytes, by the binding of spike protein $(S)$ in virus body with the angiotensin-converting enzyme 2 (ACE-2) receptor at target cells. The process of protein $S$ binding to ACE-2 receptor was also mediated by Type 2 transmembrane serine protease (TMPRSS2) in host cells, with a mechanism of ACE-2 receptor cleavening, which further mediated the entry of the virus into host cells (10). ACE2 and TMPRSS2 experience expression in target host cells, especially alveolar epithelial cells type II $(8,9)$.

Similar to other respiratory diseases caused by viruses, lymphopenia can occur in COVID-19 patients due to the degradation of T-lymphocytes due to SARS-CoV-2 infection. Another possible mechanism is due to the viral inflammatory response consisting of innate and adaptive immune responses (humoral and cellular immunity) which can disrupt the lymphopoiesis process and increase lymphocyte apoptosis (12). Although upregulation of the ACE2 receptor of 
ACE2 receptor blocking drugs and angiotensin has been predicted to increase susceptibility to SARS-CoV2 infection, a previous observation group found no association between drugs and risk of infection or death in hospital due to COVID-19 (13).

In a more advanced phase, when viral replication increases rapidly, the integrity of the epithelial-endothelial barrier is damaged. Furthermore, in epithelial cells, SARS-CoV2 infection exists as pulmonary capillary endothelial cells can accentuate the inflammatory response and trigger the entry of monocytes and neutrophils (14).

In the severe phase, activation of fulminant coagulation and ingestion of clotting factors occurs. A study from Wuhan, China, showed that 71 out of 183 people who died from COVID-19 fit the criteria for intravascular coagulation diffusion. Severe inflammation of the pulmonary tissue and pulmonary endothelial cells can lead to microthrombus formation and also to a high incidence of thrombotic complications, such as deep vein thrombosis, arterial thrombotic complications (eg. ischemic stroke, leg ischemia, myocardial infarction), and pulmonary embolism in critically ill patients (15). Viral sepsis is one of the lifethreatening state that could occur as a complication and causes organ dysfunction. It is precipitated by an uncontrolled host response to infection, which can lead to multiple organ failure (16).

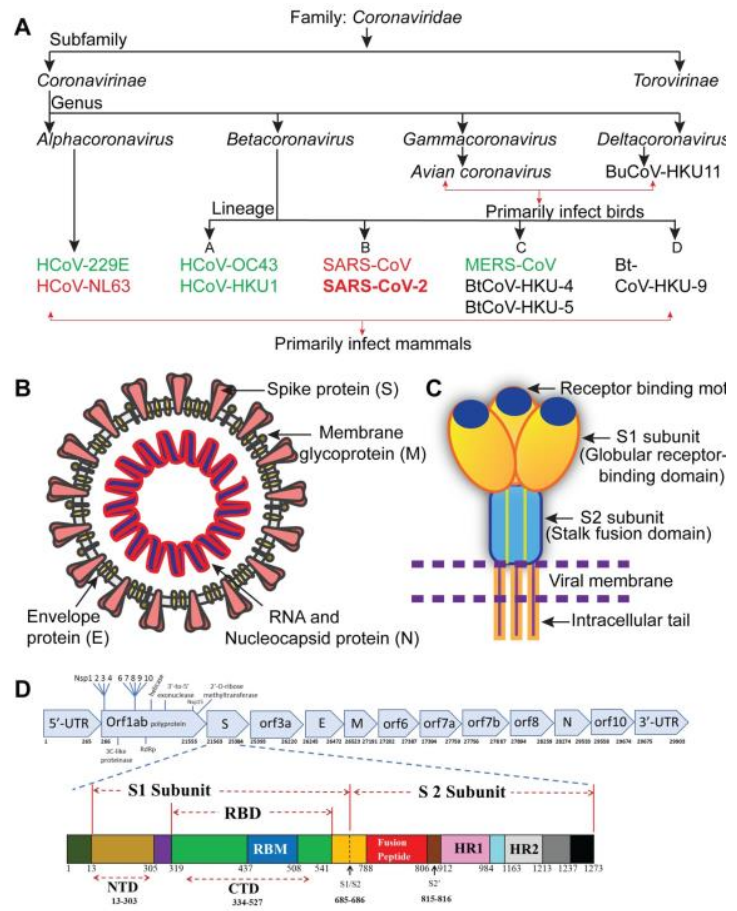

Figure 1. (A). Classification of the 7 reported HCoVs shown as green and red. HCoVs in red bind ACE2 host receptor. (B) Schematic structure of SARS-CoV-2. (C). Key features and trimeric structure of SARS-CoV-2. (D) Schematic SARSCoV-2 genome and S-Protein (Mittal et al., 2020) (30)

\section{ELDERLY IS THE MOST RISK FACTORS OF COVID-19}

Elderly population and comorbidities have been widely reported as the main factors of susceptibility due to covid-19. Age over 60 years is considered to be a major risk factor for the worsening of the condition of COVID-19 patients (2).

Comorbid is one of the main etiologies of the worsening status of COVID-19 infection, which is found in 32$60 \%$ of cases. The specific percentages of comorbid diseases include 16-20\% diabetes, $15-41 \%$ hypertension, and 14$15 \%$ for chronic obstructive pulmonary disease and cardiovascular disease (17). This seems to be the impact of this increase in age on the decline in health status associated with vital organs due to degenerative processes. In addition, age- 
related damage to several physiological functions of several organs including the respiratory system and mucociliary clearance caused by foreign particles or microorganisms can occur (18). Aging can lead to changes in lung physiology, pathology and function during pulmonary infection, affecting responsiveness and tolerance in older patients (2).

In the neurological system, aging can increase the production of interleukin-6 (IL-6) and microglia in the brain, suggesting increased expression on voltage-activated $\mathrm{K}+$ channels, which has the potential to increase IL-6 production and neurological inflammation by age. In innate and adaptive immunity, membrane regulation potential and calcium ingress are characterized by the potential for equilibration of $\mathrm{K}+(\mathrm{KV} 1.3, \mathrm{KCa} 3.1), \mathrm{Na}$ + (TRPM4), and Cl-channels in the plasma membrane. Immune function disorders through ion signaling have a significant effect on increasing susceptibility to COVID-19 (19).

Strict and prolonged lockdowns have been initiated in many areas to prevent the spread of SARS-CoV-2, limiting physical activity and its impact on stress due to social isolation. These factors can then worsen the health condition of the elderly, and contribute to the worsening of the health status of the elderly. Social restrictions and social disconnection can lead to depression state and anxiety in the elderly population which can be an increased risk of worsening outcomes due to covid-19 infection. In addition, complications secondary to general care and management are required to treat elderly patients during treatment. These complications include an increased risk of venous thromboembolism, infection of blood vessels due to catheterization, pressure ulcers, risk of falls, and delirium (1).

\section{THE EFFECT OF DEGENERATION PROCCESS TO VULNERABILITY OF SARS-COV2 INFECTION}

The natural deterioration of organ's function in elderly, especially in immune and nervous system lead to the higher risk of getting infected by SARS-CoV-2 and higher risk of turning into severe condition $(6,20)$. In immune system, there are some changes including decrease in the function of innate and adaptive immune system, including decrease in total well functioned B-cells; the continuous production of inflammatory mediators and cytokine, called ïnflammaging, could make the cytokine storm become more severe; decrease in the function of ciliary cells in respiratory, causing a decreased in clearing mechanism of respiratory tract $(5,6)$.

Meanwhile in nervous system, physiologically there are some particular changes that involve in vulnerability of SARS-CoV-2 infection. Decrease in neurotransmitter, including dopamine and serotonin, causing a decrease in neurogenesis and increase in the amount of monoamine oxide (MO). The higher level of MO could increase the oxidative stress, ended up with cells death. Together with the damages from SARS-CoV-2 infection, this could lead into the more severe state of disease (3); increased in blood brain barrier (BBB) permeability and make it easier for the virus to infect the nervous system (4); Thickening of the blood vessels in brain, resulting in increased vascular resistance and decrease in perfusion of blood. The hypercoagulability state of SARS-CoV-2 infection can also worsen the reduce in blood perfusion (7). 
THE MECHANISMS OF SARS-COV-2 INFECTION TO CENTRAL NERVOUS SYSTEM (CNS)

Based on prior studies, it is acknowledged that SARS-CoV-2 has higher possibility to infect CNS tissues. Two possible mechanisms of how SARS-CoV-2 could enter and infect CNS are spreading through direct and indirect pathway. In direct way, SARS-CoV could infect the CNS through the cribiform plate and olfactory bulb, which explain how anosmia could be one of the clinical manifestation of SARS-CoV2 's infection. After replication in cribiform plate and olfactory bulb, the virus invade some areas of the brain including areas of respiratory control, causing inflammation and demyelinating process $(3,8)$. Interestingly, the expression of Angiotensin-Converting Enzyme 2 receptors (ACE-2) are higher in the area of brain that closely involved in respiratory cycle, the ventrolateral medulla and the nucleus of tractus solitarius. In the other hand some studies showed that SARSCoV-2 can also inhibit the spontaneous breathing and possibly becoming another cause of respiratory failure, beside the direct damage of the respiratory tract cells $(8,21)$.

In an indirect way, the SARS-CoV-2 could spread through hematogenous pathway in which the virus is entering the systemic circulation to cerebral circulation.
The endothelial damage by the virus itself, facilitate the invasion to the brain tissues and cerebrospinal fluid (CSF) (8,21). Another pathway to enter the CNS is by infecting the peripheral neuron system at respiratory tract and gastrointestinal tract (GI tract). In GI tract, it infected the sympathetic afferent neurons of the enteric nervous system (ENS) and continued invading the CNS. Meanwhile in the respiratory tract, it is believed that COVID19 gained an access through peripheral nerve terminals of the respiratory network (Figure 2) (3,21).

Once the neuron tissue is being infected, the virus started to disseminate and spread through neurotransmitters pathways such as serotonergic dorsal raphe system or hematogenously through the Virchow-Robin spaces. Started from the peripheral neuron, they were transmitted by active transport, synaptic terminals and retrograde transport to the neuronal cell body in some areas of the brain. Studies in mice showed that in acute phase of infection, the virus caused a myelin loss and myelin destruction within 2-3 weeks post infection $(8,21)$.

\section{NEUROLOGICAL MANIFESTATION}

Neurological symptoms of COVID-19 infection are divided into several categories, based on location and severity as showed in Table 1. 


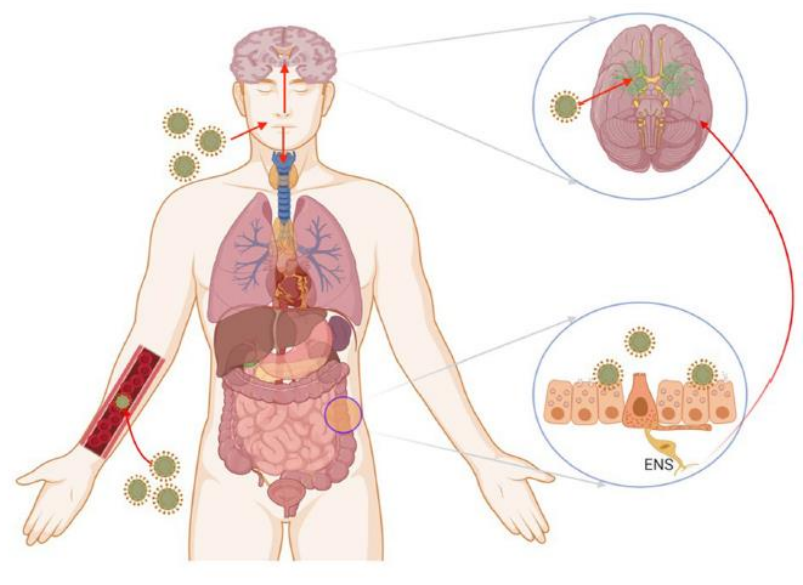

Figure 2. Coronavirus infections mechanism and neurological damage caused by SarsCoV-2. The coronavirus enter the nervous system directly through the olfactory nerve, blood circulation, ACE2 in brainstem, immune injry, and neuronal pathways, resulting in neurological disorder. The Covid-19 infection in the gastrointestinal tract could also use the Enteric Nervous System (ENS) and its afferent neurons to CNS (Khatoon et al., 2020) (21)

Table 1. Clinical manifestations of neurological deterioration $(8,21,22)$

\begin{tabular}{|c|c|}
\hline \multirow{3}{*}{ Severity } & Mild: Myalgia, dizziness, fatigue, \\
\hline & $\begin{array}{l}\text { Moderate: Anosmia, hypogueusia, } \\
\text { visual alteration, encephalopathy, } \\
\text { epilepsy, paralysis, and altered } \\
\text { consciousness }\end{array}$ \\
\hline & 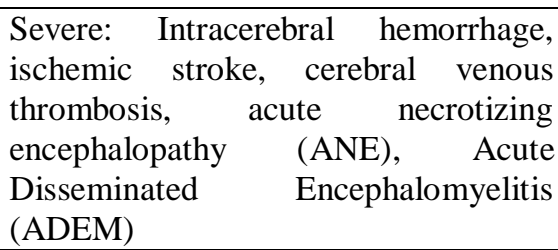 \\
\hline \multirow[t]{2}{*}{ Location } & $\begin{array}{l}\text { Central Nervous System (CNS): } \\
\text { Encephalitis, meningitis, intracerebral } \\
\text { hemorrhage, ischemic stroke, cerebral } \\
\text { venous thrombosis, acute necrotizing } \\
\text { encephalopathy } \\
\begin{array}{l}\text { Disseminated } \\
\text { (ADEM), Encephalomyelitis }\end{array} \\
\text { (ADE) Acute }\end{array}$ \\
\hline & $\begin{array}{l}\text { Peripheral Nervous System (PNS): } \\
\text { Mononeuropathy, polineuropathy, } \\
\text { Guillain-Barre Syndrome (GBS) }\end{array}$ \\
\hline
\end{tabular}

\section{CNS MANIFESTATIONS}

The central nervous system manifestations are ranging from headache, epilepsy, ataxia, encephalitis, encephalomyelitis, altered conscioussness, Acute Hemorrhagic Necrotizing Encephalopathy (ANE), and Acute Disseminated Encephalomyelitis (ADEM). Study in mice showed that dissemination of the virus in the neuronal tissues developed into encephalitis in several months, and ended up with neuronal degeneration (8).

Wong et. al reported one case from UK, a 40 year old man that was admitted to hospital with history of cough with sputum, fever, sand progressive shortness of breath for 10 days. His nasopharyngeal swab was positive for SARS-CoV-2. During medical treatment at hospital, at the third day he experienced a disorder of gait, mild bilateral fascial weakness, diplopia, oscillopsia, altered tongue movement to both sides, right deviation of tongue when it was protruded, hiccups and a decreased sensation on right arm. Another neurological tests were normal. A magnetic resonance imaging of brain and spine suggested a rhombencephalitis/myelitis, showing a swelling and micro bleeding of right inferior cerebellar peduncle and spread to the spinal cord (23).

Another interesting case is a 24 year old man who experienced a headaches, generalized fatigue and fever, and admitted at the hospital with generalized seizures and altered consciousness. A brain MRI showed alteration in the right wall of the lateral ventricle, the right mesial temporal lobe,s and hippocampus. The RT-PCR analysis for CSF tested positive, but the RT-PCR of nasopharyngeal specimen was negative. Clinical and laboratory was suggestive of a viral meningoencephalitis (24).

Acute Disseminated Encephalomyelitis (ADEM) reportedly occurred in one of COVID-19 patient aged 15 y.o, that presented with positive SARSCoV-2 in CSF and nasopharyngeal swab 
(8). Another severe case of COVID, ANE, was found in a middle age woman who admitted to hospital with cough, fever, and altered mental status (24).

\section{PNS MANIFESTATIONS}

The manifestations of PNS infection are also ranging, including the disruption to neuron system and musculoskeletal system. The most common manifestations were anosmia, chemosensory dysfunction, mononeuropathy, polyneuropathy, myelitis, and myopathy $(8,21)$. Some recent studies showed that SARS-CoV-2 infection could lead into Guillain-Barre Syndrome (GBS) in ten days after getting infected, meanwhile it took 3 weeks in myopathy and neuropathy (8). Kang Zhao et al reported a case of acute myelitis on a 66 year old man, who experienced fever, myalgia, acute flaccid paralysis of the lower limbs and sensory level at $\mathrm{T}-10$, and uncontrollable bowel and urinary function (21).

\section{EPIDEMIOLOGY OF NEUROLOGICAL MANIFESTATIONS}

Some different studies reported that neurological manifestations of SARS-CoV2 infection were quite common recently. A data from Mao et al study in Wuhan showed approximately $36.4 \%$ from 214 patients were admitted to hospital with neurological manifestations, $24.7 \%$ with CNS symptoms, $8.9 \%$ with PNS symptoms, and the last $10.7 \%$ with skeletal muscle injury symptoms. Another review from Ellul et al showed that 19 from 901 patients of COVID-19 were experiencing neurological alterations (25). Recent study from Liotta et all in Illinois, showed that 250 from 509 patients of COVID-19 had neurological symptoms, despite typical symptoms of
COVID-19 and encephalopathy patients were older than without the symptoms (26).

\section{NEUROLOGICAL MANIFESTATION IN ELDERLY POPULATION}

In general, the typical symptoms of COVID-19 infection in elderly are fever, cough, headache and diarrhea. Meanwhile the atypical symptoms are delirium, low grade fever, and abdominal pain $(5,6)$. The most frequent manifestations of neurological disorder in COVID-19 infection are encephalopathy, delirium, and Cerebrovascular Disease (CVD) but still, there are no specific neurological symptoms in elderly population $(4,26,27)$. The CVD commonly happened in elderly, both as a prior condition that increasing the severity of COVID-19 or as a complication of COVID-19 infection. It is also believed that some neurodegenerative disorders such as Parkinsons Disease (PD) and Alzheimer could get worsen after being infected by SARS-CoV-2 (6).

There is still no complete explanation about the correlation between PD and the severity of COVID-19 infection, but Eleopra et al. study demonstrated that PD patients that were also infected by COVID19 experienced a worsening disfunction of motor and non-motor system, especially in urinary and gastrointestinal system. The possible mechanism discussed is SARSCoV-2 infection could accelerate the process of Lewy-Body formation by causing an accumulation of the alphasynuclein (aSyn) protein $(6,28)$.

On the other hand, patients with Alzheimer could also experience a worsening symptoms because of COVID19. A retrospective study from Acute Hospital in Brescia province, Northern Italy, demonstrated that COVID-19 patient with Dementia had higher mortality for 
about $40 \%$ in approximately (29). But still, further research about the mechanism of SARS-CoV-2 infection in progression of Alzheimer disease symptoms is needed.

\section{CONCLUSION}

Regardless of age, the infection of SARSCoV-2 to both central and peripheral nervous system could lead into range of neurological deteriorations, in which also ranging in forms and severity. In elderly patients, despite of comorbidities, the natural degeneration process is likely being a risk factor of more severe neurological symptoms. In this review, we have described the possible correlation between degeneration process to the vulnerability of SARS-CoV-2 infection, the mechanism of infection to nervous system, and some possible neurological symptoms caused by it specifically among elderly patients. Although it has not been completely explained yet and still continuously being studied, it has been being a consideration of future diagnostic approach and treatment especially in elderly population.

\section{ACKNOWLEDGEMENT}

The author acknowledged major assistance from academics who carried out the citations on his articles in the preparation of this review. The author also thanks the editor/publisher for every articles and journals that is the source of literature that has been discussed and reviewed in this article.

\section{CONFLICT OF INTEREST}

There is no conflict of interest among the authors.

\section{REFERENCES}

1. Garnier-Crussard A, Forestier E, Gilbert T, Krolak-Salmon P. Novel
Coronavirus (COVID-19) Epidemic: What Are the Risks for Older Patients? Vol. 68, Journal of the American Geriatrics Society. 2020. p. 939-40.

2. Liu K, Chen $\mathrm{Y}$, Lin $\mathrm{R}$, Han $\mathrm{K}$. Clinical features of COVID-19 in elderly patients: A comparison with young and middle-aged patients. J Infect. 2020 Jun;80(6):e14-8.

3. Peters R. Ageing and the brain. Postgrad Med J. 2006 Feb;82(964):84-8.

4. Erickson M, Banks W. AgeAssociated Changes in the Immune System and Blood-Brain Barrier Functions. Int J Mol Sci [Internet]. 2019 Apr 2;20(7):1632. Available from: https://www.mdpi.com/14220067/20/7/1632

5. Perrotta F, Corbi G, Mazzeo G, Boccia M, Aronne L, D'Agnano V, et al. COVID-19 and the elderly: insights into pathogenesis and clinical decision-making. Aging Clin Exp Res. 2020 Aug;32(8):1599-608.

6. Ferini-Strambi L, Salsone M. COVID-19 and neurological disorders: are neurodegenerative or neuroimmunological diseases more vulnerable? J Neurol [Internet]. 2020 Jul 21;1-11. Available from: https://pubmed.ncbi.nlm.nih.gov/32 696341

7. Trollor JN, Valenzuela MJ. Brain ageing in the new millennium. Aust N Z J Psychiatry. 2001 Dec;35(6):788-805.

8. Montalvan V, Lee J, Bueso T, De Toledo J, Rivas K. Neurological manifestations of COVID-19 and other coronavirus infections: A systematic review. Clin Neurol Neurosurg [Internet]. 2020 
Jul;194:105921. Available from: https://linkinghub.elsevier.com/retri eve/pii/S030384672030264X

9. Harapan $\mathrm{H}$, Itoh $\mathrm{N}$, Yufika A, Winardi W, Keam S, Te H, et al. Coronavirus disease 2019 (COVID19): A literature review. J Infect Public Health. 2020 May;13(5):66773.

10. Wan Y, Shang J, Graham R, Baric RS, Li F. Receptor Recognition by the Novel Coronavirus from Wuhan: an Analysis Based on Decade-Long Structural Studies of SARS Coronavirus. Gallagher T, editor. J Virol [Internet]. 2020 Mar 17;94(7):1-9. Available from: http://jvi.asm.org/content/94/7/e001 27-20.abstract

11. Oh S-J, Lee JK, Shin OS. Aging and the Immune System: the Impact of Immunosenescence on Viral Infection, Immunity and Vaccine Immunogenicity. Immune Netw [Internet]. 2019 Nov 14;19(6):e37e37. Available from: https://pubmed.ncbi.nlm.nih.gov/31 921467

12. Sungnak W, Huang N, Bécavin C, Berg M, Queen R, Litvinukova M, et al. SARS-CoV-2 entry factors are highly expressed in nasal epithelial cells together with innate immune genes. Nat Med. 2020 May;26(5):681-7.

13. Fosbøl EL, Butt JH, Østergaard L, Andersson C, Selmer C, Kragholm $\mathrm{K}$, et al. Association of AngiotensinConverting Enzyme Inhibitor or Angiotensin Receptor Blocker Use With COVID-19 Diagnosis and Mortality. JAMA. 2020 Jul;324(2):168-77.

14. $\mathrm{Xu} \mathrm{Z,} \mathrm{Shi} \mathrm{L,} \mathrm{Wang} \mathrm{Y,} \mathrm{Zhang} \mathrm{J,}$
Huang L, Zhang C, et al. Pathological findings of COVID-19 associated with acute respiratory distress syndrome. Vol. 8, The Lancet. Respiratory medicine. 2020. p. 420-2.

15. Tang N, Li D, Wang $X$, Sun Z. Abnormal coagulation parameters are associated with poor prognosis in patients with novel coronavirus pneumonia. J Thromb Haemost [Internet]. 2020/03/13. 2020 Apr;18(4):844-7. Available from: https://pubmed.ncbi.nlm.nih.gov/32 073213

16. Klok FA, Kruip MJHA, van der Meer NJM, Arbous MS, Gommers DAMPJ, Kant KM, et al. Incidence of thrombotic complications in critically ill ICU patients with COVID-19. Thromb Res [Internet]. 2020/04/10. 2020 Jul;191:145-7. Available from: https://pubmed.ncbi.nlm.nih.gov/32 291094

17. Huang C, Wang Y, Li X, Ren L, Zhao J, Hu Y, et al. Clinical features of patients infected with 2019 novel coronavirus in Wuhan, China. Lancet (London, England). 2020 Feb;395(10223):497-506.

18. Dent E, Martin FC, Bergman H, Woo J, Romero-Ortuno R, Walston JD. Management of frailty: opportunities, challenges, and future directions. Lancet (London, England). 2019 Oct;394(10206):1376-86.

19. Dhama K, Patel SK, Kumar R, Rana J, Yatoo MI, Kumar A, et al. Geriatric Population During the COVID-19 Pandemic: Problems, Considerations, Exigencies, and Beyond. Front public Heal 
[Internet]. 2020 Sep 22;8:574198. Available from: https://pubmed.ncbi.nlm.nih.gov/33 072713

20. Daroedono E, Siagian FE, Alfarabi M, Cing JM, Arodes ES, Sirait RH, et al. The impact of COVID-19 on medical education: our students perception on the practice of long distance learning. Int J Community Med Public Heal. 2020;7(7):2790.

21. Khatoon F, Prasad K, Kumar V. Neurological manifestations of COVID-19: available evidences and a new paradigm. J Neurovirol [Internet]. 2020;26(5):619-30. Available from: https://doi.org/10.1007/s13365-02000895-4

22. Abboud H, Abboud FZ, Kharbouch $\mathrm{H}$, Arkha Y, El Abbadi N, El Ouahabi A. COVID-19 and SARSCov-2 Infection: Pathophysiology and Clinical Effects on the Nervous System. World Neurosurg [Internet]. 2020/05/28. 2020 Aug;140:49-53. Available from: https://pubmed.ncbi.nlm.nih.gov/32 474093

23. Wong PF, Craik S, Newman P, Makan A, Srinivasan K, Crawford E, et al. Lessons of the month 1: A case of rhombencephalitis as a rare complication of acute COVID-19 infection. Clin Med. 2020 May;20(3):293-4.

24. Moriguchi T, Harii N, Goto J, Harada D, Sugawara H, Takamino J, et al. A first case of meningitis/encephalitis associated with SARS-Coronavirus-2. Vol. 94, International journal of infectious diseases. 2020. p. 55-8.

25. Ellul MA, Benjamin L, Singh B,
Lant S, Michael BD, Easton A, et al. Neurological associations of COVID-19. Lancet Neurol. 2020 Sep;19(9):767-83.

26. Liotta EM, Batra A, Clark JR, Shlobin NA, Hoffman SC, Orban $\mathrm{ZS}$, et al. Frequent neurologic manifestations and encephalopathyassociated morbidity in Covid-19 patients. Ann Clin Transl Neurol [Internet]. 2020 Nov 5;7(11):222130. Available from: https://onlinelibrary.wiley.com/doi/ 10.1002/acn3.51210

27. Rahman A, Niloofa R, De Zoysa IM, Cooray AD, Kariyawasam J, Seneviratne SL. Neurological manifestations in COVID-19: A narrative review. SAGE Open Med [Internet]. 2020 Jan 10;8. Available from:

http://journals.sagepub.com/doi/10. 1177/2050312120957925

28. Poyiadji N, Shahin G, Noujaim D, Stone M, Patel S, Griffith B. COVID-19-associated Acute Hemorrhagic Necrotizing Encephalopathy: Imaging Features. Radiology. 2020 Aug;296(2):E11920.

29. Bianchetti A, Rozzini R, Guerini F, Boffelli S, Ranieri P, Minelli G, et al. Clinical Presentation of COVID19 in Dementia Patients. J Nutr Health Aging [Internet]. 2020;24(6):560-2. Available from: https://pubmed.ncbi.nlm.nih.gov/32 510106

30. Mittal A, Manjunath K, Ranjan RK, Kaushik S, Kumar S, Verma V. COVID-19 Pandemic: Insight into structure function, and hACE2 receptor recognition by SARS-CoV2. PLOS Pathogens. 2020. 